\title{
Poesia visual no Brasil: \\ Wlademir Dias Pino e Tchello \\ D’Barros
}

Visual poetry in Brazil: Wlademir Dias Pino and

Tchello D'Barros

Poesía Visual en Brasil: Wlademir Dias Pino e

Tchello D'Barros

Revista Dissertar No30 V.1 ANO XIV

DOI: $10.24119 / 16760867$ ed114248

Data de submissão: 23-10-2018

Data de aceite: $30-10-2018$

por Renata da Silva de Barcellos ${ }^{1}$

\section{Resumo}

A comunicação tem objetivo de apresentar meu objeto de estudo do projeto de Pós-doutorado em construção. Trata-se de dois grandes poetas visuais brasileiros, com uma vasta produção a ser estudada e difundida:WaldemirDias-PinoeTchellod'Barros.Este,contemporâneo, integrando exposições, material didático, revistas literárias... no Brasil e no mundo com belas críticas de curadores. Aquele, um dos pioneiros da poesia visual no Brasil, com suas contribuições como a importância da obra Enciclopédia visual.

Palavras-Chave: imagem - palavra - mídia.

\section{Abstract}

The communication aims to present my object of study of the postdoctoral project under construction. These are two great Brazilian visual poets, with a vast production to be studied and disseminated: Waldemir Dias-Pino and Tchello d'Barros. This, contemporary, integrating exhibitions, didactic material, literary magazines ... in Brazil and in the world with beautiful critics of curators. He, one of the pioneers of visual poetry in Brazil, with his contributions as the importance of the work Visual Encyclopedia.

1Renata da Silva de Barcellos: Possui graduação Letras / Francês pela Universidade Federal Fluminense (1996), mestrado em Letras pela Universidade Federal Fluminense (2003), doutorado em ESTUDOS DE LINGUAGEM pela Universidade Federal Fluminense (2008) e Pós-doutorado em Língua Portuguesa pela UFRJ (2015). Atualmente é professora na UNICARIOCA de Comunicação e expressão e de Oficina e no Colégio Estadual José Leite Lopes de Língua Portuguesa e de Produção textual. Tem experiência na área de Letras, com ênfase em produção textual e gramática. Autora das obras Gramática contextualizada e Itens do Novo Enem, coautora de Antologias poéticas e autora de diversos artigos sobre o ensino da Língua Portuguesa.e-mail: prof.renatabarcellos@gmail.com 
Keywords: image - word - media.

\section{Resumen}

La comunicación tiene objetivo de presentar mi objeto de estudio del proyecto de postdoctorado en construcción. Se trata de dos grandes poetas visuales brasileños, con una vasta producción a estudiar y difundir: Waldemir Dias-Pino e Tchello d'Barros. Este, contemporáneo, integrando exposiciones, material didáctico, revistas literarias... en Brasil y en el mundo con bellas críticas de curadores. Aquel, uno de los pioneros de la poesía visual en Brasil, con sus contribuciones como la importancia de la obra Enciclopedia visual.

Palabras clave: Imagen; Palabra; Médios de comunicación.

La poesía visual no es dibujo, ni pintura, es un servicio a la comunicación". Joan Brossa

\section{Introdução}

Este texto consiste em uma breve reflexão sobre a temática da poesia visual no Brasil. Cabe ressaltar que de todas as leituras feitas até o presente momento de livros, artigos, dissertações e teses, constatouse o quão ainda há pouco estudo na área e nos poetas aqui escolhidos Waldemir Dias-Pino e Tchello d'Barros. Ainda vale destacar a polêmica: o que fazem é poesia ou arte? A partir disso, será apresentada algumas considerações.

Com os movimentos de Vanguarda e as novas percepções de poesia, em sua elaboração, passa-se considerar o meio como parte significante da leitura, não mais mero suporte sem expressão sígnica. Assim, no Brasil, segundo Álvaro de Sá, seria possível classificar a poesia visual em três vertentes distintas: (1) a construtiva, defendida pelos integrantes do grupo Noigandres, formado inicialmente por Augusto de Campos, Haroldo de Campos e Décio Pignatari e, mais tarde também por Ronaldo Azeredo e José Lino Grünewald; (2) a funcional, apresentada por Wlademir Dias-Pino, precursora do livro-poema e do movimento poema/processo e (3) a expressiva, cujo principal representante foi Ferreira Gullar, defendendo uma posição fenomenológica e mais subjetiva, surgindo o Neoconcretismo (derivado do Concretismo). Esta proposta de classificação é válida por proporcionar um panorama deste período de efervescente produção.

Partindo dessa proposta de classificação de Álvaro de Sá, será apresentada uma síntese da parte teórica. $\mathrm{O}$ artigo é constituído de três partes: poesia visual, Waldemir Dias Pino e Tchello d'Barros.

\section{Poesia visual}

Em meio a uma efervescência de descobertas no mundo como: Psicanálise, Teoria da relatividade, vanguardas artísticas, criação da publicidade, avanço do cinema, dentre outos, após a Semana de 
Arte Moderna de 1922 (momento de ruptura com padrões estéticos ainda vigentes, tentativa de autonomia literária e linguística do Brasil), eis que surgem novos experimentos na área de linguagem e agrega uma cartografia em movimento: a poesia visual. Segundo Philadelpho Meneszes (1975), ela passa a ser uma forma central da poesia de todas as vanguardas de nosso século. É entendida como o conjunto inumerável de composições poéticas (pré)dominantemente visuais criadas desde a Antiguidade greco-latina, passando pela Idade Média, pelo Renascimento, pelo Barroco, pelo Modernismo, até os dias atuais....

Poesia visual remonta a expressão italiana <poesia visiva>, por volta de 1960, designava pesquisas verbo-visuais. Há uma acepção de experiência artística de vanguarda, remetendo ao período modernista do final do século XIX e início do XX, conforme explica Philadelpho Menezes (ibid p.14). Entretanto, ele é mais específico: refere-se a um fenômeno poético do século XX, no qual o cruzamento das linguagens é decorrência direta do panorama visual das grandes cidades e dos meios de comunicação de massa.

No Brasil, a expressão "poesia visual" é (muitas vezes) empregada para se referir à produção situada a partir de 1970, caracterizada pela incorporação indiscriminada de imagens gráficas no interior do poema, ao extremo de se efetuar a desaparição da palavra. Um tipo, portanto, de experiência visual distinta das concretistas e neoconcretistas, mais ligada ao poema processo (MENEZES, 1991). Dessa forma, o poeta adota uma técnica e, através do fazer poético, descobre novas fronteiras no campo literário. E, por sua vez, o leitor é convidado a praticar o exercício do olhar e ver para captar a imagem retroprojetada.

A poesia visual visa trabalhar as características plásticas da escrita ressaltando os valores visuais, espaciais, considerando-a como uma mancha gráfica, um desenho, uma relação de figurafundo na folha, como a admiração de um arabesco cujo significado da grafia desconhecemos. Segundo E. M. de Melo e Castro (1993), no aspecto visual, o signo interpretante é especificamente sincrônico, compacto, sintético, espacial, concreto. A poesia não só como símbolos representativos de uma sonoridade anterior à própria escrita, mas sim como uma escrita tácita na qual por si mesma já é forma carregada de sentido. A página não mais considerado como um acúmulo de letras, mas um suporte espacial ativo, como a tela de uma pintura.

A partir dos anos 70, a poesia visual, elaborada basicamente através do meio gráfico (livro, cartaz e gravura), busca novos meios de suporte. Surgem assim os primeiros poemas performances. Segundo o poeta português Fernando Aguiar (1985), esses possuem uma série de componentes que podem ser explorados esteticamente. Conceitos como o tempo, o espaço, o movimento/ação, a tridimensionalidade, a cor, o som, o cheiro, a luz e, principalmente, a presença do poeta como 
detonador e fator de consecução do poema.

Vale destacar ainda que de acordo com Melo e Castro (1993), a poesia visual é representada de forma expressiva quatro vezes na história da arte ocidental: durante o período alexandrino, na renascença carolíngea, no período barroco e no século XX. Pode observar-se ainda que cada um desses se relaciona com o fim de um período histórico e começo de uma nova época. Ela data de 300 anos a.C, na Alexandria, as tecnofanias de Sírnias de Rodes constituem os primeiros poemas visuais conhecidos. São elas: "O Machado", "As Asas" e "O Ovo". Este poema era uma espécie de caligrama, cuja definição é «texto (ger. um poema) cujas linhas ou caracteres gráficos formam uma figura relacionada com o conteúdo ou a mensagem do texto» (cf. Dicionário Houaiss da Língua Portuguesa).

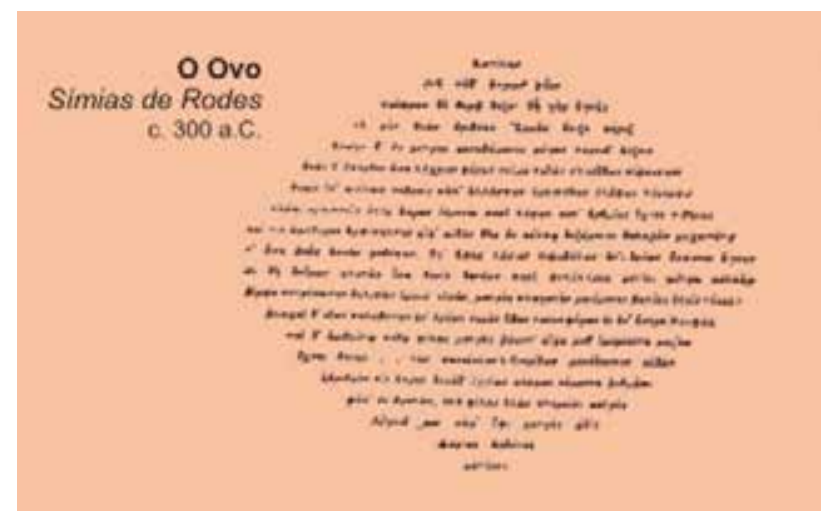

A poesia visual desenvolve sua vertente mais "plástica", tridimensional, ocupando espaços em galerias de arte, museus e locais públicos. Os constantes da poesia visual contemporânea são:

a)a identidade entre ikon e logos;

b)o nexo espacial da poesia;

c)a concretização da referência textual no ato de leitura;

d)o predomínio de objetivos

No Brasil, de acordo com Antônio Miranda, a poesia visual surge como é "uma tentativa de romper com a ditadura da forma discursiva do poema, de vencer o domínio da gramática ou mesmo de superar a construção prosística na poesia" (2008, p. 24). O uso simultâneo de signos verbais e não verbais como recurso na poesia visual e considerando ser antes a mensagem transmitida pela imagem, quase sempre sem necessitar do recurso da palavra. A seguir, isso será verificado em dois representantes do Brasil: Wlademir Dias-Pino e Tchello d Barros. 


\section{Wlademir Dias-Pino}

Wlademir Dias-Pino, nascido no Rio de Janeiro em 24 de abril de 1927, no bairro da Tijuca, poeta, artista visual e artista gráfico. Em virtude de perseguição política, seu pai transfere-se com a família em 1936 para Cuiabá, onde passa a juventude. Em 1939, com 12 anos de idade, edita na gráfica de seu pai que era tipógrafo, seu primeiro livro: Os Corcundas. Em 1948, em Cuiabá, funda o movimento literário de vanguarda Intensivismo.

A criação dele foi anunciada com manifesto no jornal Sacy, editado pelo grupo. Segundo o poeta, este movimento propunha intensificar o sentido da imagem na poesia, propunha uma superposição de imagens, o que nós chamamos de leitura de vértices. [...] Com isso nós tentávamos substituir o sentido de adjetivação da poesia e estabelecer um código do suporte. Já trabalhávamos com a questão da posição da palavra no suporte da página, a leitura por posição da palavra, como é na matemática o número. Nós propúnhamos também uma leitura contínua. [...] Com isso quebra-se o sentido de verso, porque o verso é uma linha debaixo da outra. Quando você vai colocar a palavra pela potencialidade, pela posição no espaço, você automaticamente quebra o sentido de verso. E como estabelecer uma leitura para essa escrita? Através de gráficos. [...] Isto foi, acredito, a grande novidade do intensivismo: encontrar um indicador de leitura. Assim ele se liberta do sentido temático, da unidade temática de um poema tradicional.

Em 1951, o "Manifesto do Intensivismo" foi publicado sete anos antes do "Plano piloto para a poesia concreta" (1958). Isso deve ser destacado pelo fato de que um dos seis poetas participantes da Exposição Nacional de Arte Concreta foi Wlademir Dias-Pino de (1956/1957). Aconteceu em São Paulo e depois no Rio de Janeiro, contemplou as artes plásticas, a literatura, a escultura e a gravura. Dessa forma, escritura e inscrição; feitura e modelação; traços e decodificação todos conviveram em um mesmo espaço expositivo. E a fusão de todos esses elementos influenciou as poéticas visuais surgidas, no território nacional, a partir da década de 1950. Cabe destacar que, em 2009, foi criada e aprovada em 18 de novembro a Lei $n^{\circ}$ 9.244, deputado estadual Alexandre Cesar, a fim de reconhecer o Intensivismo, segmento literário e cultural nascido em Mato Grosso, como forma de manifestação cultural popular, com os direitos respeitados e suas histórias resguardadas e ensinadas nas escolas do estado.

Conforme Moacy Cirne , a importância de 1956 para a história da Literatura Brasileira pode ser registrada mediante três episódios capitais: olançamento da poesia concreta, a publicação deGrande sertão: veredas e o surgimento de A ave, de Wlademir Dias-Pino, livro que se liga(va) às virtualidades gráficas e verbo-visuais do concretismo, mas que apontava para um desdobrar novo nas aventuras composicionais da própria poesia concreta.". Nela, versos como "A ave voa dentro de sua cor" têm as palavras espalhadas pelas páginas, que vinham soltas, 
numa caixa, permitindo ao leitor recriar o poema.

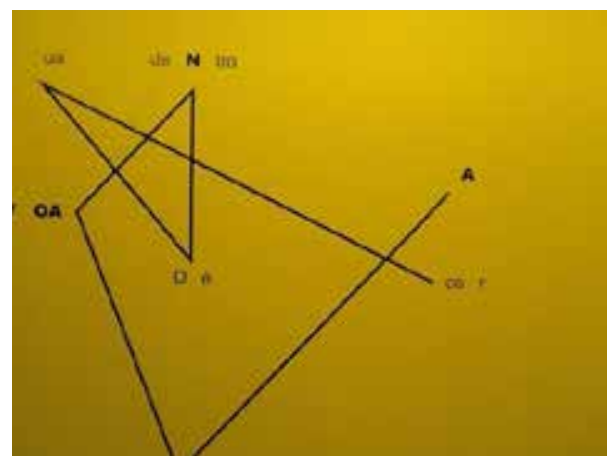

O poeta e ensaísta Alckmar Luiz dos Santos (UFSC), em seu Leitura de nós: ciberespaço e literatura, destaca que um dos aspectos mais "intrigantes" da poesia concreta é o fato de não ter sido elaborada (realmente) uma criação verbovisual. De acordo com Santos, talvez só a obra de Wlademir Dias-Pino, em sua totalidade, autorize falar numa criação poética em que verbal e visual se confrontam e se conjugam num mesmo plano de expressão, colocando na relação entre eles a única possibilidade de leitura. Possibilitando com isso o surgimento de uma terceira via, de uma outra linguagem, de uma retórica não mais subordinada exclusivamente à visual ou à verbal (2003, p. 86). Vale destacar que enquanto a paranomásia é a principal característica do Concretismo, Dias-Pino trabalha com o simbólico e o metafórico, buscando uma espécie de metáfora pura. Wlademir é autor também de dois outros livros fundamentais da literatura brasileira: SOLIDA e Numéricos.

$\mathrm{Na}$ década seguinte, liderou vanguardistas de todo o país no grupo Poema/processo. Aos 89 anos, produziu em sua casa, no Rio, trabalhos desafiantes dos limites entre gêneros, como a "Enciclopédia visual'. Ela consiste em uma série de centenas de colagens que revê a história das imagens na cultura ocidental. De acordo com DiasPino, em um bate-papo no MAR, com Evandro Salles, o curador da mostra: "Sou um pensador gráfico. Nunca me interessei pela dimensão narrativa da literatura, quis explorar a dimensão visual. Se alguém disser que o que faço não é literatura... não ligo para gêneros. Mas a base de tudo para mim é o poema".

No que se refere à Enciclopédia Visual (1970-2016), ela consiste em uma espécie de inventário de imagens com 1001 volumes divididos em 28 séries. Cada uma contendo 36 volumes e cada volume contendo 36 páginas. Nessas imagens coletadas na iconografia universal sobre uma infinidade de temas (dos desenhos pré-históricos à história em quadrinhos, dos primórdios da escrita às linguagens computadorizadas, dos clássicos da pintura ao imaginário da publicidade). Elas são coletadas em diversas fontes e depois trabalhadas pelo artista em 
camadas que se superpõem, sendo articuladas umas às outras, coloridas e modificadas.

Durante muitos anos, o método preferencial de trabalho do artista foi o recorte e a colagem, reelaborando as imagens por meio de um sistema de cópias e recolagem. Nos últimos anos de sua vida, sua opção foi de trabalhar diretamente a imagem digitalizada.. Essas são compostas a partir de conteúdos apropriados de várias origens e épocas. O resultado são figuras com tratamento industrial, constituídas de múltiplas camadas: um repositório de conteúdos visuais formados por um amálgama de imagens entre formas e cores empregadas pelo artista. Lamentavelmente, parte dela foi destruída por uma infiltração na casa do artista, no Rio de Janeiro.

De acordo com o Museu de Arte do Rio, o que diferencia a enciclopédia wlademiriana das demais é sua forma de organização não é ordinal, mas cardinal: não há verbetes em ordem alfabética para organizar os temas com suas ilustrações; mas coleções de imagens reunidas em torno de temas e que trazem em si toda a carga informativa que possuem e que o artista reconfigura potencializando e rearticulando seus conteúdos e significados.

Muito tem-se a pesquisar ainda sobre a vasta obra de Dias-Pino. Para concluir esta brevíssima consideração, será mencionada a visão dele sobre a polêmica: é poesia visual ou arte? Segundo ele, a leitura visualizada também é um poema mas diferenciado da tradicional formatação.

\section{Tchello D'Barros}

Tchello d' Barros é um ser não só inquieto (como ele mesmo define-se) como também provocador de "inquietação" a quem lê sua obra pela forma como desbrava a linguagem na sua múltipla forma de expressão. Interagindo nas diferentes modalidades das Artes, deixa impresso em cada trabalho o produto do que seu olhar sobre objeto analisado foi capaz de captar. Segundo ele, essa diversidade de "experimentos alternativos, um conjunto de trabalhos produzidos resulta de uma necessidade interna de interferir na realidade, de lutar no mundo que me cerca com as armas que tenho: as criações no campo da arte".

Ele é escritor e artista visual nascido em Brunópolis (SC) em 1967. Morou em 15 cidades por enquanto, realizou atividades culturais em todos os Estados do Brasil, deambulou por 20 países e desde 2013 está radicado no Rio de Janeiro (RJ). Atua profissionalmente como desenhista, editor, curador e produtor cultural. Estudou Literatura como aluno ouvinte no Curso de Letras na Furb (SC) e Pintura no ateliê livre na mesma instituição; Cursou História da Arte na Fundaj (PE); atualmente estuda Cinema/Audiovisual na UFRJ (RJ). Foi professor na Faculdade Senac (SC) e na pós-graduação da Faculdades Hélio Alonso - Facha (RJ). Ministra diversas oficinas literárias (conto, crônica, 
poesia, roteiro, narrativa ficcional) em eventos e instituições culturais. Além dos 6 livros que publicou, seus contos, crônicas e artigos vêm sendo publicados também em mais de 50 coletâneas, antologias e livros didáticos, além de veicular seus escritos regularmente em diversos meios impressos e virtuais. Tem itinerado pelo Brasil com a mostra Convergências, uma retrospectiva de sua produção em Poesia Visual, já percorreu vários Estados. Suas obras visuais já participaram de cerca de 150 exposições.

Ao analisar a sua poesia visual, observa-se os seguintes temas: tempo (relógio - efemeridade) - natureza (borboleta - pomba) traição - amor - relação (pronome pessoal: eu - tu - nós) - política (vários termos correlatos a esta temática como impunidade - desvio - propina...) - soneto (forma clássica) - olho... cujo caráter é crítico, social, político e econômico sobre os diversos aspectos do cotidiano. Dentre todos os temas abordados, vale destacar que existem duas de suas obras com a palavra <olho> no título: Olho nu (1996) e Olho zen (1996). Este tema não só é presente em sua obra como também pode-se definir o artista como<olhos de Lince>, pela sua capacidade de ver a palavra fragmentada e a de captar simultaneidade de sons, imagens e palavras.

A simultaneidade e o experimentalismo linguístico unem-se como recurso permitindo ao poeta ora fundir vocábulos procurando um efeito diferente do usual, ora cortá-los, criando outros novos vocábulos formados pela fragmentação de um primeiro. Ele explora as potencialidades do signo linguístico, buscando na relação, palavra/ imagem, atingir os limites possíveis de captação e subversão do signo. Como declarou em uma entrevista, a poesia "se infiltra em todos os meandros do labirinto da minha vida. Começo pela manhã no banheiro e vai até na madrugada quando adormeço - a dor - meço". Até neste momento, percebe-se como ele é de olhar, ver e fragmentar a palavra atribuindo-lhe novos significados. Assim, ao "penetrar surdamente no reino das palavras" (Drummond), insere a poesia em novos espaços que pedem novos leitores, novos olhares.

Dessa forma, em toda sua obra, fica latente a demonstração de uma inquietação em relação à forma como as relações são construídas no mundo (valores...). Um exemplo já está presente em seu primeiro poema visual Preconceito, 1993 disponível em https:/ / www.facebook. com/tchellodbarros/media_set?set=a.1134587095063\&type=3.

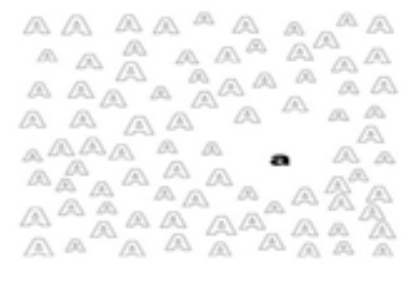


Neste poema, através da sobreposição da letra A, representando cada indivíduo na sociedade, verifica-se aquele que sofre preconceito por ser diferente seja na maneira de pensar seja por uma deficiência. Alguém que escapa do padrão totalmente. Não se enquadra no mundo que o circunda. Não aceita o sistema como ele nos é imposto. Isso é percebido na forma gráfica a letra $\mathrm{A}$ : em minúsculo e negrito.

Analisando este e toda produção de Tchello d' Barros, percebeuse que a dialética (cujo termo em grego é dialektiké) atravessa os temas abordados. Além da questão de remeter à oposição de ideias sobre uma mesma questão, segundo Demo, a dialética consiste em um "convite insistente à discussão e à prática, à criatividade, ao diálogo crítico e produtivo" (1990, p. 134). Essa será nossa hipótese a ser ratificada, na pesquisa do Pós-Doutorado. Pode-se observar esta característica em:

Agora

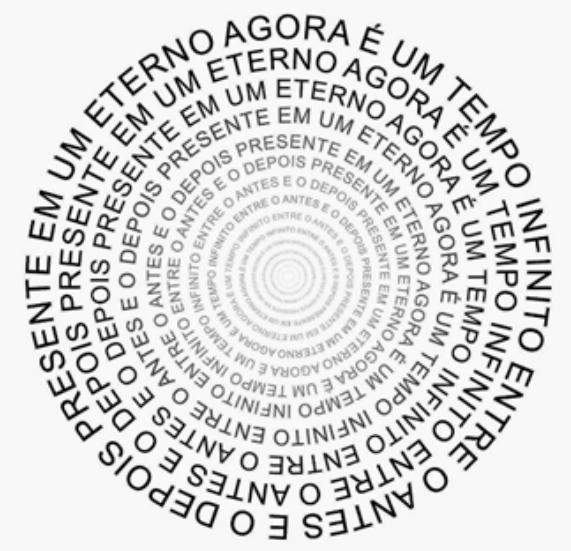

Neste poema visual, Tchello traz a temática do tempo recorrente em sua obra através do aspecto gráfico: infinito e o jogo de palavras dentro deste mesmo campo semântico (antes - depois - agora eterno...) desenhando-o. Tratando assim de um poema metalinguístico: a palavra é utilizada para retratar seu próprio sentido. Cabe destacar também a característica transversal a toda a sua produção: a dialética. Pode-se comprovar isso como os vocábulos: <antes e depois> em contraponto com <eterno e infinito>.

Em outras poesias visuais, há a temática do aspecto socialpolítico como em: 


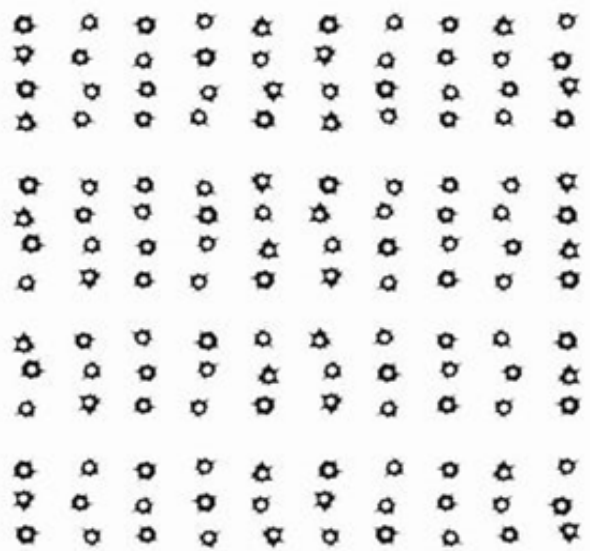

Tchello d'Barros apresenta o formato do soneto (14 versos compostos em 2 quartetos e tercetos para retratar a temática da ditadura. Cada imagem gráfica representa um tiro e este simboliza uma sílaba do verso. Pode-se inferir que o título é ambíguo por não só remeter ao fato histórico como também a uma crítica ao modelo clássico imposto até o período do Modernismo.

Dessa forma, a partir desta breve abordagem, ratifica-se os "olhos de lince" do poeta inquieto Tchello d'Barros cuja dialética é uma característica presente em sua obra nas diversas temáticas. Podese dizer ainda quanto a este seu olhar sobre a vida, o mundo e o modo como transforma o que lhe toca em poesia visual ser instigante. Leva o leitor a refletir sobre a questão tratada e o seu modo de produção.

Subversão

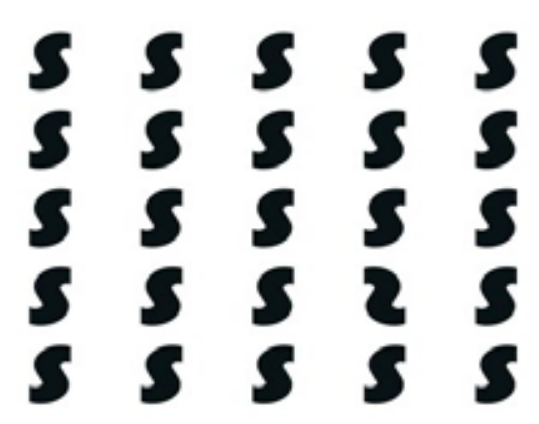


Este poema visual de Tchello d' Barros é um exemplo daquela categoria que apresenta um único signo fora do padrão. São ordenados de forma quase idêntica, até ser constatado o diferente. $\mathrm{O}$ elemento diferenciado, aquele ser fora do enquadramento socialmente estabelecido.

Granada

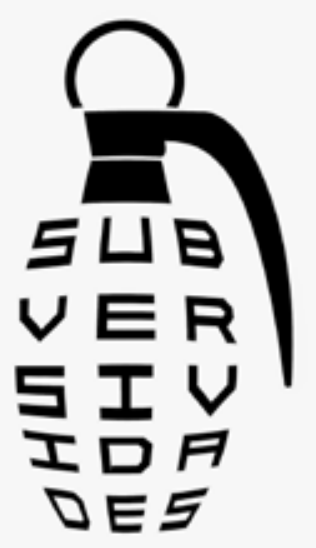

Neste poema, emformato de granada a palavra <subversidades> apresenta novas possibilidades de fragmentação e, consequentemente, de novos sentidos. A estranheza provocada pelo poeta pretende transformar um "explodir a granada". Observa-se a mais variadas possibilidades da palavra convergem para uma diversidade plurissignificante de imagens.

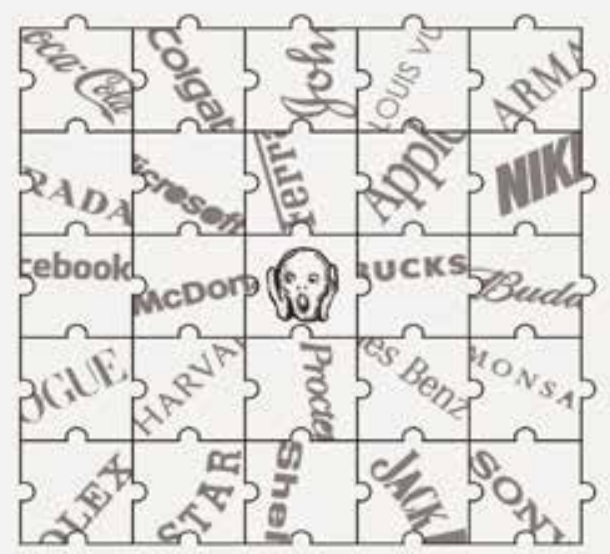




\section{"Consumai ou Excluir-se-vos-á"}

A poesia visual tem como temática um dos piores problemas sociais: o consumismo. Em forma de quebra cabeça, o poeta menciona várias marcas de produtos diversos como: Rolex, de relógio; Sony, de TV ; Star e Nike de tênis; Apple de telefone... No título, sugere que a pessoa tem duas opções: consumir ou excluir-se. Voltando assim o que tangencia sua obra: a dicotomia.

Teste de visão

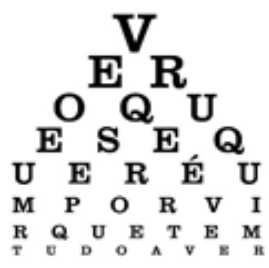

As letras soltas constituem forma de uma pirâmide e ao observar a disposição delas, lemos o seguinte texto: "Ver o que se quer é um porvir que tem tudo a ver". Podemos destacar a polissemia da palavra $<$ ver>: o primeiro, na abertura, significa <enxergar> e o segundo, no fechamento, na expressão <tudo a ver>, refere-se à <compatível> . O título Teste de visão remete à questão de o leitor ver ou não o que está escrito.

\section{Considerações finais}

A partir de um conciso panorama da Poesia Visual no Brasil e da análise de dois de seus grandes representantes, Wlademir DiasPino e Tchello d'Barros, conclui-se que há muito a ser estudado não só teoricamente como também analisada a obra dos poetas. Só a Enciclopédia visual do percursor já resulta inúmeras pesquisas com abordagens diferentes dos 28 temas. Quanto ao mais contemporâneo, d'Barros é um poeta multifacetado em plena produção. Alguém que deseja explorar as mais diferentes maneiras de comunicar e de fazer arte, um artista liberto de qualquer aprisionamento da palavra escrita e empenhado em buscar maneiras múltiplas de expressar o pensamento, o que precisa ser dito. Sua obra tem apresentado até o momento alguns aspectos: um ser inquieto, observador, desbravador daquilo que escapa, foge ao padrão, o outro lado da moeda.

De acordo com as reflexões suscitadas, conclui-se o artigo citando Omar Salomão, autor de Impreciso e À deriva. Para ele, a poesia é como "uma forma de ver, de enxergar as coisas, de desacomodar. Naturalmente, foi um caminho que me levou para esse lado das artes plásticas justamente por trazer uma liberdade estética 
maior. Muita gente que trabalha com Poesia Visual hoje passa por esse lado".(https://www.correiobraziliense.com.br/app/noticia/ diversao-e-arte/2016/03/13/interna_diversao_arte,521714/poesiacontemporanea-usa-tecnologia-para-expandir-suas-fronteiras.shtml).

\section{Referências}

AGUIAR, Fernando. 1985. Poesia ou a Intervenção Viva. Reeditado in: MENEZES, Philadelpho(Org). 1998. Poesia Sonora. São Paulo: Educ, pp. 145150.

ALMEIDA, Marinei. Wlademir Dias-Pino e o Intensivismo. Revista Ecos: variantes linguísticas literaturas regionais. Cáceres: Unemat Editora, 2004. Ano II, n. 2. p. 37-44.

BOSI, Alfredo. Dialética da colonização. São Paulo: Companhia das Letras, 1992. . História concisa da literatura brasileira. São Paulo: Cultrix, 1997.

BROSSA, J. Poesia vista. São Paulo: Ateliê, 2005.

CAMPOS, Haroldo de. A arte no horizonte do provável. São Paulo: Perspectiva, 1969. (Debates, 16).

CANDIDO, Antonio. Formação da literatura brasileira: momentos decisivos. Belo Horizonte: Itatiaia, 1997.

Castro, E. M. de Melo. Poética dos Meios e Arte High Tech. Lisboa: Ed. Veja, 1988)

Cirne, Moacy. Duas ou três coisas sobre o Poema/processo. Revista Ponto 2, Rio de Janeiro, 1968.

CHRYSOSTOMO, Luiz. O poema infinito de Wlademir Dias-Pino. Disponível em:

<http:/ / www.museudeartedorio.org.br/sites/default/files / wlademirdp_textos_exposicao.pdf > Acessado em 15/09/18.

DALATE, Sérgio. A escritura do silêncio: uma poética do olhar em Wlademir Dias Pino. Dissertação de mestrado, UNESP, 1997.

D' BARROS, Tchello. Poesia Visual/Visual Poetry-Tchello d'Barros. Disponível em: <https://pt-br.facebook.com/pages/biz/PoesiaVisual-Visual-Poetry-Tchello-dBarros-1434855403472935/> Acessado em 14/09/18.

Tchello d'Barros - Poesia Visual. Disponível em: <http:// tchellodbarros-poesiavisual.blogspot.com. Acessado em 20/09/18.> 
Facebook - Tchello d'Barros. Disponível em: <https:/ / www.facebook. com/tchellodbarros/media_set?set $=$ a. $1134587095063 \&$ ty pe $=3>$. Acesso em 20/09/18.

DIAS-PINO, Wlademir. Solida. 2. ed. Cuiabá: Igrejinha, 1962. A ave. Cuiabá: Igrejinha, 1956.

DEMO, Dialética e qualidade política, in Dialética Hoje, 1990: 134.

FILIPOUSKI, Ana Mariza Ribeiro. Literatura juvenil. São Paulo: Companhia das Letras, 2009, p.23.

MACIEL, Nahima. Poesia contemporânea usa tecnologia para expandir suas fronteiras. Disponível em:

<https://www.correiobraziliense.com.br/app/noticia/diversaoe-arte/2016/03/13/interna_diversao_arte,521714/poesiacontemporanea-usa-tecnologia-para-expandir-suas-fronteiras.shtml> Acesso em 15/09/18.

MENDONÇA, Antônio Sérgio; SÁ, Álvaro de. Poesia de Vanguarda no Brasil. Rio de Janeiro: Edições Antares, 1983, p. 167.

MENEZES, Philadelpho(Org).1998. Poesia Sonora. São Paulo: Educ, pp.138-144,1975.

Poética e visualidade: uma trajetória da poesia brasileira contemporânea. Campinas, SP: Editora da UNICAMP, 1991.

MENEZES, Philadelpho. Poética e visualidade: uma trajetória da poesia brasileira contemporânea. Campinas, SP: Editora da UNICAMP, 1975.

MIRANDA, Antonio. Wlademir Dias-Pino. Disponível em:

<http://www.antoniomiranda.com.br/poesia_visual/wladimir_ias_ pino.html> Acessado em 15/09/18.

PIGNATARI, Décio. Contracomunicação. 3. ed. ver. Cotia: Ateliê Editorial, 2004.

SÁ, Álvaro de; MENDONÇA, Antonio Sérgio. Poesia de vanguarda no Brasil: de Oswald ao poema visual. Rio de Janeiro: Antares, 1983.

SALOMÃO, Omar. Poesia contemporânea usa tecnologia para expandir suas fronteiras. In:https://www.correiobraziliense.com.br/app/ noticia/diversao-e-arte/2016/03/13/interna_diversao_arte,521714/ poesia-contemporanea-usa-tecnologia-para-expandir-suas-fronteiras. shtml 
SANTOS, Alckmar Luiz dos. Leituras de nós: ciberespaço e literatura. São Paulo: Itaú Cultural, 2003. (Rumos Itaú Cultural Transmídia). 